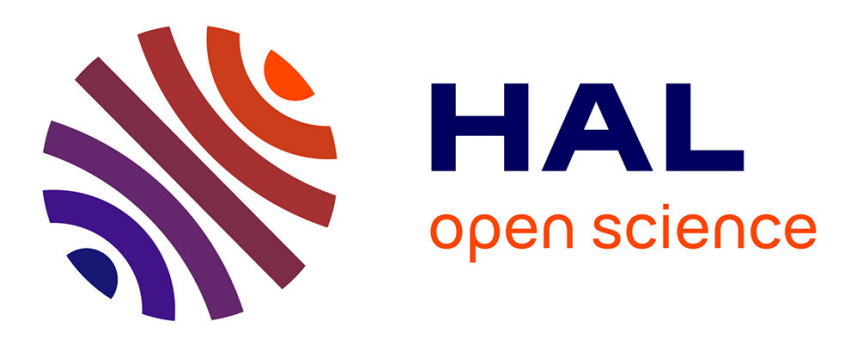

\title{
Corrosion behaviour of an assembly between an AA1370 cable and a pure copper connector for car manufacturing applications
}

\author{
Rosanne Gravina, Nadine Pébère, Adrien Laurino, Christine Blanc
}

\section{- To cite this version:}

Rosanne Gravina, Nadine Pébère, Adrien Laurino, Christine Blanc. Corrosion behaviour of an assembly between an AA1370 cable and a pure copper connector for car manufacturing applications. Corrosion Science, 2017, vol. 119, pp. 79-90. 10.1016/j.corsci.2017.02.022 . hal-01692699

\section{HAL Id: hal-01692699 \\ https://hal.science/hal-01692699}

Submitted on 25 Jan 2018

HAL is a multi-disciplinary open access archive for the deposit and dissemination of scientific research documents, whether they are published or not. The documents may come from teaching and research institutions in France or abroad, or from public or private research centers.
L'archive ouverte pluridisciplinaire HAL, est destinée au dépôt et à la diffusion de documents scientifiques de niveau recherche, publiés ou non, émanant des établissements d'enseignement et de recherche français ou étrangers, des laboratoires publics ou privés. 


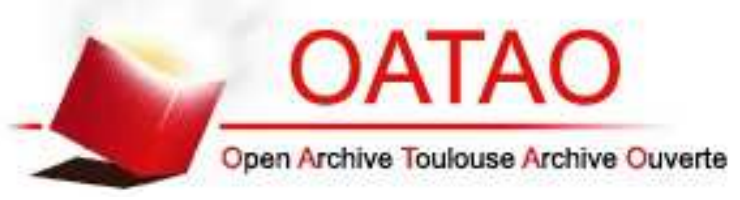

\section{Open Archive TOULOUSE Archive Ouverte (OATAO)}

OATAO is an open access repository that collects the work of Toulouse researchers and makes it freely available over the web where possible.

This is an author-deposited version published in : http://oatao.univ-toulouse.fr/ Eprints ID : 19370

To link to this article : DOI: $10.1016 / j . c o r s c i .2017 .02 .022$

URL : http://dx.doi.org/10.1016/j.corsci.2017.02.022

\section{To cite this version :}

Gravina, Rosanne and Pébère, Nadine and Laurino, Adrien and Blanc, Christine Corrosion behaviour of an assembly between an AA1370 cable and a pure copper connector for car manufacturing applications. (2017) Corrosion Science, vol. 119. pp. 79-90. ISSN 0010-938X

Any correspondence concerning this service should be sent to the repository administrator: staff-oatao@ listes-diff.inp-toulouse.fr 


\title{
Corrosion behaviour of an assembly between an AA1370 cable and a pure copper connector for car manufacturing applications
}

\author{
Rosanne Gravina $^{\mathrm{a}, \mathrm{b}}$, Nadine Pébère ${ }^{\mathrm{a}}$, Adrien Laurino ${ }^{\mathrm{b}}$, Christine Blanc $^{\mathrm{a}, *}$ \\ a CIRIMAT, Université de Toulouse, CNRS, INPT, UPS, ENSIACET, 4 allée Emile Monso, CS 44362, 31030 Toulouse, France \\ ${ }^{\mathrm{b}}$ LEONI Wiring Systems France, 5 avenue de Newton, 78180 Montigny-le-Bretonneux, France
}

\begin{abstract}
A B S T R A C T
The corrosion behaviour of an assembly between an AA1370 cable and a pure copper connector for wiring harnesses was studied in neutral chloride and sulphate containing solution. Electrochemical impedance measurements showed that the corrosion behaviour of the cable was controlled by the ingress of the electrolyte inside cable cavities. Further, local impedance measurements were performed on two assembly cross-sections, i.e. with and without cavities in the aluminium cable. The results provided evidence for both the galvanic coupling between aluminium and copper and the presence of cavities in the aluminium cable as relevant explanations for the corrosion behaviour of the assembly.
\end{abstract}

Keywords:

A. Aluminium

A. Copper

B. EIS

C. Crevice corrosion

C. Pitting corrosion

\section{Introduction}

Typical wiring harnesses in the automotive industry consist of assembly between $\mathrm{Cu}$ cable and $\mathrm{Cu}$ connector. Today, the pressure in environmental regulations led to search for solutions giving rise to fuel economy and reduction in $\mathrm{CO}_{2}$ emission. In this context, car manufacturers planned to reduce both cost and weight of wiring harnesses. One innovative solution is the substitution of $\mathrm{Cu}$ by $\mathrm{Al}$ alloys, such as AA1370, in cables. In the last years, several works concerned the manufacturing processes of this new type of assembly. Recently, different methods have been proposed to produce $\mathrm{Al}$ strands with ductility and fatigue characteristics reliable for automotive wiring harnesses [1-4] while ultrasonic welding has been used to join $\mathrm{Al}$ cable with $\mathrm{Cu}$ connector [5,6]. However, one major problem for wiring harnesses concerns their corrosion resistance because, in service, wiring harnesses are exposed to aggressive media, such as de-icing salt, which can generate corrosion damage.

Numerous data are reported in the literature concerning the corrosion behaviour of $1 \mathrm{xxx} \mathrm{Al}$ alloys. The main results concerned the influence of Fe-rich particles which act as cathodic sites and promote first dissolution of the surrounding matrix and then, pitting corrosion [7-9]. However, the corrosion behaviour of an Al cable is more complex. In the literature, only few works have been reported

\footnotetext{
* Corresponding author.

E-mail address: christine.blanc@ensiacet.fr (C. Blanc).
}

concerning the corrosion behaviour of a cable. Xu and Chen investigated the corrosion damage of wire specimens pulled from the replaced cables in Shimen Bridge [10]. They analysed the corroded cables from the sheath breakage to the cable center and explained that the extent of corrosion at any point of a cable section was controlled by its distance from the sheath breakage due to the fluid that could penetrate inside the cable [10]. Ishikawa and Kawakami [11] showed the presence of cavities inside a cable due to the incomplete penetration of the sheath rubber. Then, during exposure to an aggressive medium, the solution penetrate into the cable cavities leading to the formation of a confined environment. Depending on the configuration of the harness, e.g. number of strand arms constitutive of the cable and space between them, and the intrinsic corrosion behaviour of the strand, the confined electrolyte composition should evolve rapidly, e.g., oxygen concentration, cations concentration and $\mathrm{pH}$, and then induce severe corrosion phenomena, such as crevice corrosion [12-14]. Chanel and Pebere studied the mechanisms governing the degradation of brass-coated steel cords for tyres in a $0.25 \mathrm{M} \mathrm{Na}_{2} \mathrm{SO}_{4}$ solution in contact with air and maintained at $25^{\circ} \mathrm{C}$ by using electrochemical impedance spectroscopy (EIS) [15]. They showed that EIS was a suitable technique to quantify the corrosion resistance of a cable [15]. Moreover, the assembly between an $\mathrm{Al}$ cable and a $\mathrm{Cu}$ connector should generate galvanic corrosion due to the difference in corrosion potential values between the two metals in aqueous solution [16-21]. Khedr and Lashien investigated the corrosion behaviour of pure $\mathrm{Al}$ in $\mathrm{Cu}^{2+}$ rich solutions and showed the accelerating effect of the $\mathrm{Cu}^{2+}$ cations 
Al corrosion rate due to $\mathrm{Cu}$ deposition and subsequent galvanic coupling [17,18]. Jorcin et al. [19] showed, for a model couple constituted of $\mathrm{Al}$ and $\mathrm{Cu}$, the chemical dissolution of $\mathrm{Al}$ due to a $\mathrm{pH}$ increase at the $\mathrm{Al} / \mathrm{Cu}$ interface; this generated an occluded zone in which the composition of the electrolyte $\left(\mathrm{a}^{10^{-3}} \mathrm{M} \mathrm{Na}_{2} \mathrm{SO}_{4}\right.$ solution in contact with air and at room temperature) evolved rapidly. The galvanic coupling between $\mathrm{Al}$ and $\mathrm{Cu}$ was also investigated in a $10 \mathrm{mM} \mathrm{Na}_{2} \mathrm{SO}_{4}$ solution by using a thin-layer cell in order to model the occluded zone in the crevice [20]. Joma et al. performed experiments in a $0.1 \mathrm{M} \mathrm{Na}_{2} \mathrm{SO}_{4}$ solution and showed that the chemistry in a thin-layer cell plays a significant role at least at a local scale [21].

The present work contributes to get a better insight of the mechanisms governing the degradation of an AA1370 cable/pure $\mathrm{Cu}$ assembly with a particular attention to the effect of the electrolyte ingress inside the cable. Conventional electrochemical measurements ( $E_{\text {corr }}$ measurements, polarisation curves and electrochemical impedance spectroscopy) were first carried out for the AA1370 cable in order to investigate the corrosion behaviour of the cable alone. Given that the cable was made of a large number of strands, the electrochemical measurements were also performed for AA1370 strands to have a better understanding of the corrosion mechanisms. Then, to investigate the corrosion behaviour of the AA1370 cable - Cu connector assembly, local electrochemical impedance (LEIS) measurements were performed on two crosssections of the assembly, one cross-section corresponding to an AA1370 cable with cavities and the other one without cavities. LEIS is a non-destructive electrochemical technique that has been used in recent years to study localized corrosion on bimetallic surface [19,22-26]. It was used here to determine the influence of the cavities in the AA1370 cable after welding on the galvanic corrosion processes occurring for the AA1370 cable/Cu connector assembly.

\section{Experimental}

\subsection{Materials}

The assembly was obtained by ultrasonic welding using a DS 20 II apparatus between an AA1370 (99.7\% Al, 0.072\% Fe, 0.0045\% Mg, $0.045 \% \mathrm{Si}$; wt.\%) cable and a pure $\mathrm{Cu}(99.90 \mathrm{wt} . \% \mathrm{Cu} ; 200-400 \mathrm{ppm}$ $\mathrm{O}_{2}$ ) connector. The $\mathrm{Cu}$ connector was a hot stamped $\mathrm{Cu}$ sheet. In the following, the AA1370 cable in the assembly will be referred to as 'the Al part'; the AA1370 cable/Cu connector assembly will be referred to as $\mathrm{Al} / \mathrm{Cu}$ assembly. During the welding process, the cable (without the polymer shell) was positioned on the Cu connector and a pressure was exerted. Then, ultrasonic vibrations were applied so that the cable and the Cu connector moved relatively to one another with an oscillating movement. This led to a friction between the two metals and then to the formation of a welding zone. The total length of the welded zone was about $12 \mathrm{~mm}$. The quality of the welding depends mainly on the applied pressure and on the amplitude of the vibrations. There was a short zone $(8 \mathrm{~mm})$ where the strands constitutive of the cable were entirely welded together so that the cable did not reveal any cavities after the welding, this zone being called as the 'effective welded zone'.

The galvanic coupling at the $\mathrm{Al} / \mathrm{Cu}$ interface was studied by electrochemical measurements performed on two cross-sections of the assembly. Fig. 1a shows a global picture of the assembly. The two selected cross-sections are shown in Fig. 1b and c. One of the cross-sections was removed from a porous zone of the cable due to the fact that the strands constitutive of the cable were not entirely welded together (henceforth called 'assembly with cavities') (Fig. 1b). Another cross-section was removed from the effective welded zone where no cavities were observed between the welded strands (henceforth called 'assembly without cavities')
(Fig. 1c). Before corrosion tests, the cross-sections were embedded in an epoxy-resin without filling the cavities. This was achieved by embedding the cross-sections in a parafilm shell.

For a better understanding of the corrosion behaviour of the assembly, electrochemical measurements were also performed for cross-sections of both the AA1370 cable before welding and AA1370 strands constitutive of the cable. The cross-sections were perpendicular to the cable/strand axis. The cable was an assembly of 50 strands $(0.52 \mathrm{~mm}$ diameter $)$ protected by a plastic insulating sleeve. Fig. 1d shows an optical observation of a cross-section of a cable where the 50 strands can be observed. It can be seen that the space between the strands is not uniform. To perform the electrochemical measurements, the cable was embedded in an epoxy-resin without filling the space between the strands (see the procedure for the assembly). If only the surface perpendicular to the cable axis was taken into account, the surface area of the cross-section of the cable with 50 strands exposed to the electrolyte during the electrochemical experiments was $0.11 \mathrm{~cm}^{2}$. To study the corrosion behaviour of a strand, the difficulty was its diameter, i.e. $0.52 \mathrm{~mm}$. Three electrodes were prepared with the cross-sections of 1 strand $\left(S=0.002 \mathrm{~cm}^{2}\right), 4$ strands $\left(S=0.008 \mathrm{~cm}^{2}\right)$ and 22 strands $\left(S=0.047 \mathrm{~cm}^{2}\right)$ respectively exposed to the electrolyte. For the 3 electrodes, the strands were organized to obtain a regular arrangement of their cross-sections (the axis of each individual strand being parallel to the others) and embedded together in an epoxy-resin. All the cavities between the strands were filled by the epoxy-resin. Preliminary experiments showed that similar results were obtained for the 3 electrodes. However, the reproducibility of the measurements was better for the electrode with 22 strands due to the fact that the surface was more representative of the alloy microstructure. In the following, for brevity, only the results for the electrode with 22 strands are presented. This electrode was referred to as 'strand sample'. It could be noted here that the corrosion behaviour of the strand sample could be considered representative of the behaviour of a cable for which the cavities would be sealed. Electrochemical measurements were also performed for a Cu sample taken off a connector used for the assembly; the surface exposed to the electrolyte was $0.11 \mathrm{~cm}^{2}$.

Before all electrochemical tests, the surface of the specimens was mechanically abraded with successive grit SiC papers (1200, 2400 ) and then polished from 6 to $1 \mu \mathrm{m}$ grade with diamond paste and deionised water as lubricant.

\subsection{Electrochemical measurements}

All electrochemical measurements were performed in sulphate and/or chloride-containing solutions; they are assumed to be representative of the automotive environments. Several authors have used sulphate and/or chloride-containing solutions to study $\mathrm{Al} / \mathrm{Cu}$ galvanic coupling allowing the results obtained in this work to be compared with their results $[20,21]$. For the conventional electrochemical measurements ( $\mathrm{E}_{\text {corr }}$ measurements, polarization curves and impedance measurements), the corrosive medium $(\mathrm{pH}=6.5)$ was prepared from deionised water by adding $0.1 \mathrm{M} \mathrm{Na}_{2} \mathrm{SO}_{4}$ and a small concentration of chloride $(0.001 \mathrm{M} \mathrm{NaCl})$. For LEIS experiments, a $0.001 \mathrm{M} \mathrm{NaCl}$ solution $(\mathrm{pH}=6.5)$ prepared from deionised water was chosen to maintain a low conductivity required to optimize the measurements in the low-frequency range [27]. The electrolyte was maintained at a temperature of $25^{\circ} \mathrm{C} \pm 1^{\circ} \mathrm{C}$ except for the LEIS measurements performed at room temperature $\left(22^{\circ} \mathrm{C} \pm 1^{\circ} \mathrm{C}\right)$.

For the conventional electrochemical measurements, the experimental set-up consisted of a three-electrode cell, connected to a Biologic VSP apparatus, with a large platinum electrode used as counter electrode and a saturated calomel electrode (SCE) as reference electrode. Specimens used as the working electrode were 


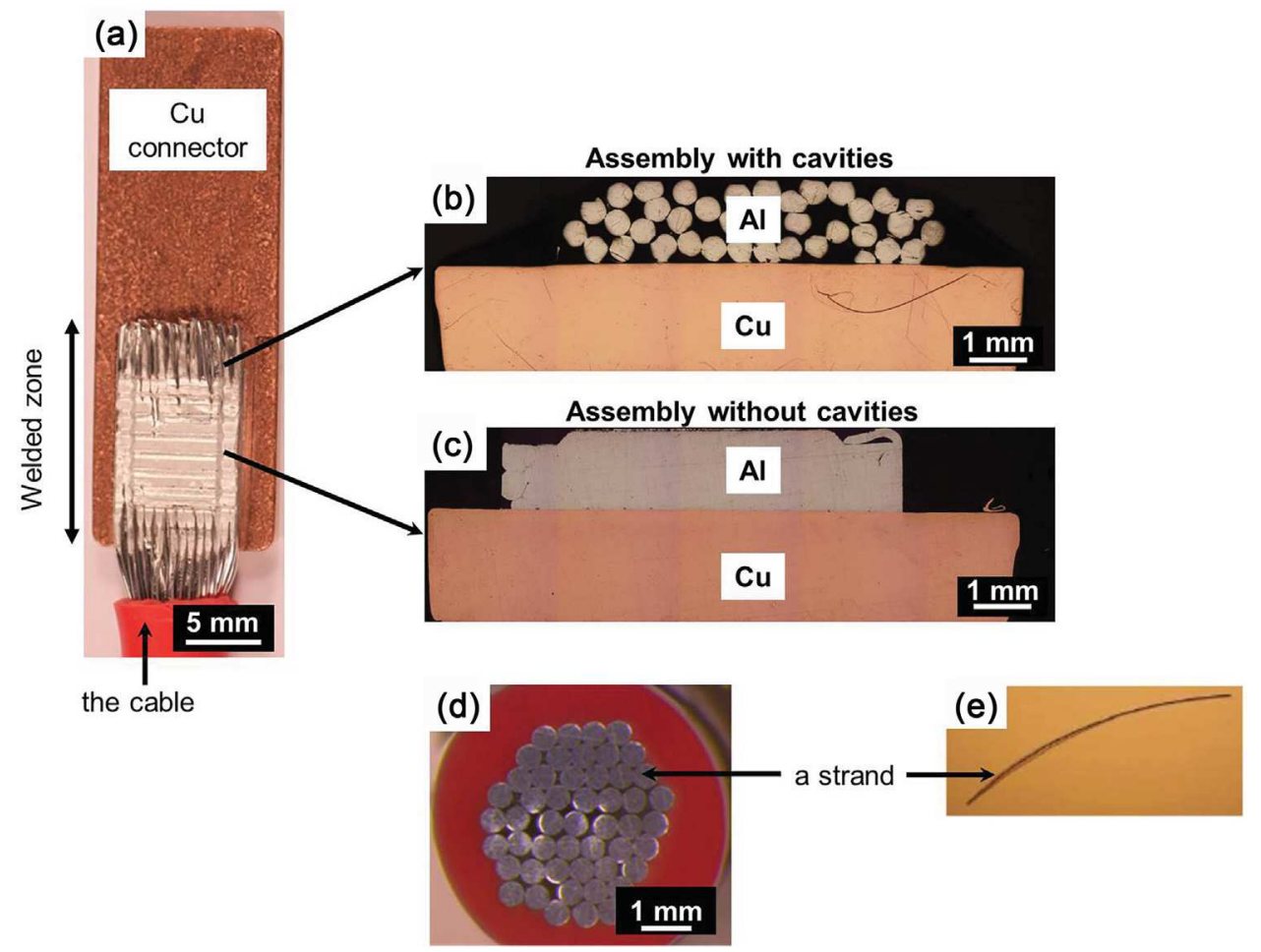

Fig. 1. (a) Global view of the assembly between AA1370 cable and pure Cu connector; cross-sections of the assemblies (b) with and (c) without cavities; (d) the AA1370 cable and (e) a strand.

the strand sample and the cable. For the two cross-sections of the assembly, only $\mathrm{E}_{\text {corr }}$ was measured for exposure times to the electrolyte ranging from $1 \mathrm{~h}$ to $168 \mathrm{~h}$. In the figures, mean values of $\mathrm{E}_{\mathrm{corr}}$ are given on the basis of at least ten experiments for each experimental condition. For the polarization curves, the samples were first exposed to the electrolyte at $\mathrm{E}_{\text {corr }}$ for $3 \mathrm{~h}$ and then, the anodic and cathodic parts were obtained independently from $\mathrm{E}_{\mathrm{corr}}$ at a potential sweep rate of $0.07 \mathrm{mV} \mathrm{s}^{-1}$. For each sample, at least three curves were plotted to check the reproducibility. Impedance measurements were performed under potentiostatic conditions at $\mathrm{E}_{\text {corr }}$ with a $15 \mathrm{mV}$ peak-to-peak sinusoidal perturbation. Frequency was swept downwards from $65 \mathrm{kHz}$ to $3 \mathrm{mHz}$ with 9 points per decade. Several impedance diagrams were recorded as a function of time ranging from $3 \mathrm{~h}$ to $168 \mathrm{~h}$. All impedance measurements were repeated three times to check the reproducibility.

The corrosion behaviour of the $\mathrm{Al} / \mathrm{Cu}$ assembly was studied by local electrochemical impedance spectroscopy (LEIS). The measurements were carried out with a Solartron 1287 Electrochemical Interface, a Solartron 1255B frequency analyser and a Scanning Electrochemical Workstation Model 370 (Uniscan Instruments). This method used a five-electrode configuration. The probe (i.e., a bi-electrode allowing local current density measurements) was stepped across a selected area of the sample. The analysed part had an area of $8 \mathrm{~mm} \times 14 \mathrm{~mm}$ and the step size was $500 \mu \mathrm{m}$ in the $x$ and $y$ directions. Maps were obtained at a fixed frequency, chosen in the present case at $10 \mathrm{~Hz}$, and admittance was plotted rather than impedance to improve the visualization of the result [28]. Local impedance diagrams were recorded over a frequency range of $65 \mathrm{kHz}-3 \mathrm{~Hz}$ with 8 points per decade. Spectra were plotted for the 2 cross-sections of the assembly shown in Fig. $1 \mathrm{~b}$ and $\mathrm{c}$ from the $\mathrm{Cu}$ part to the $\mathrm{Al}$ part with the origin of axis being the $\mathrm{Al} / \mathrm{Cu}$ interface. The time to record all the local impedance diagrams was lower than $60 \mathrm{~min}$. For all the LEIS measurements, the spatial resolution was about $1 \mathrm{~mm}^{2}$, i.e. the analysed surface was about $1 \mathrm{~mm}^{2}$ when a local impedance diagram was plotted [27]. For the assembly with cavities (Fig. 1b), the cavities corresponded to $20 \%$ of the analysed surface so that the effective metallic surface was only $80 \%$ of the analysed surface (analysis performed on the cross-section perpendicular to the cable axis). In the following, for LEIS results, the impedance values (in $\Omega \mathrm{cm}^{2}$ ) are not corrected. Therefore, for the assembly with cavities, the impedance values are overestimated with an error of about 20\% if only the surface exposed to the bulk solution is taken into account.

\subsection{Surface characterization}

AA1370 surfaces were observed before and after the electrochemical tests by using a Nikon Eclipse MA200 optical microscope (OM). A Leo 435VP scanning electron microscope (SEM) was used to visualize the $\mathrm{Al} / \mathrm{Cu}$ assembly after different exposure times to the electrolytic solution and to obtain a better description of the corrosion morphology, particularly at the $\mathrm{Al} / \mathrm{Cu}$ interface. For all the observations, the samples were removed from the electrolyte after the electrochemical tests, rinsed with deionised water and then air-dried.

\section{Experimental results and discussion}

First, the corrosion behaviour of the cable, as compared to the strand sample, was studied by combining stationary and impedance measurements. Then, attention was paid to the corrosion behaviour of the $\mathrm{Al} / \mathrm{Cu}$ assembly.

\subsection{Electrochemical behaviour of the $A A 1370$ cable}

Fig. 2 shows OM observations of a strand and of the cable after two exposure times ( $3 \mathrm{~h}$ and $168 \mathrm{~h}$ ) to the aggressive solution at their corrosion potential. For both samples, a weak dissolution of the matrix around the Fe-rich particles, identified as $\mathrm{Al}_{3} \mathrm{Fe}$ particles [29], was observed [7-9]. However, comparison of Fig. 2a and 

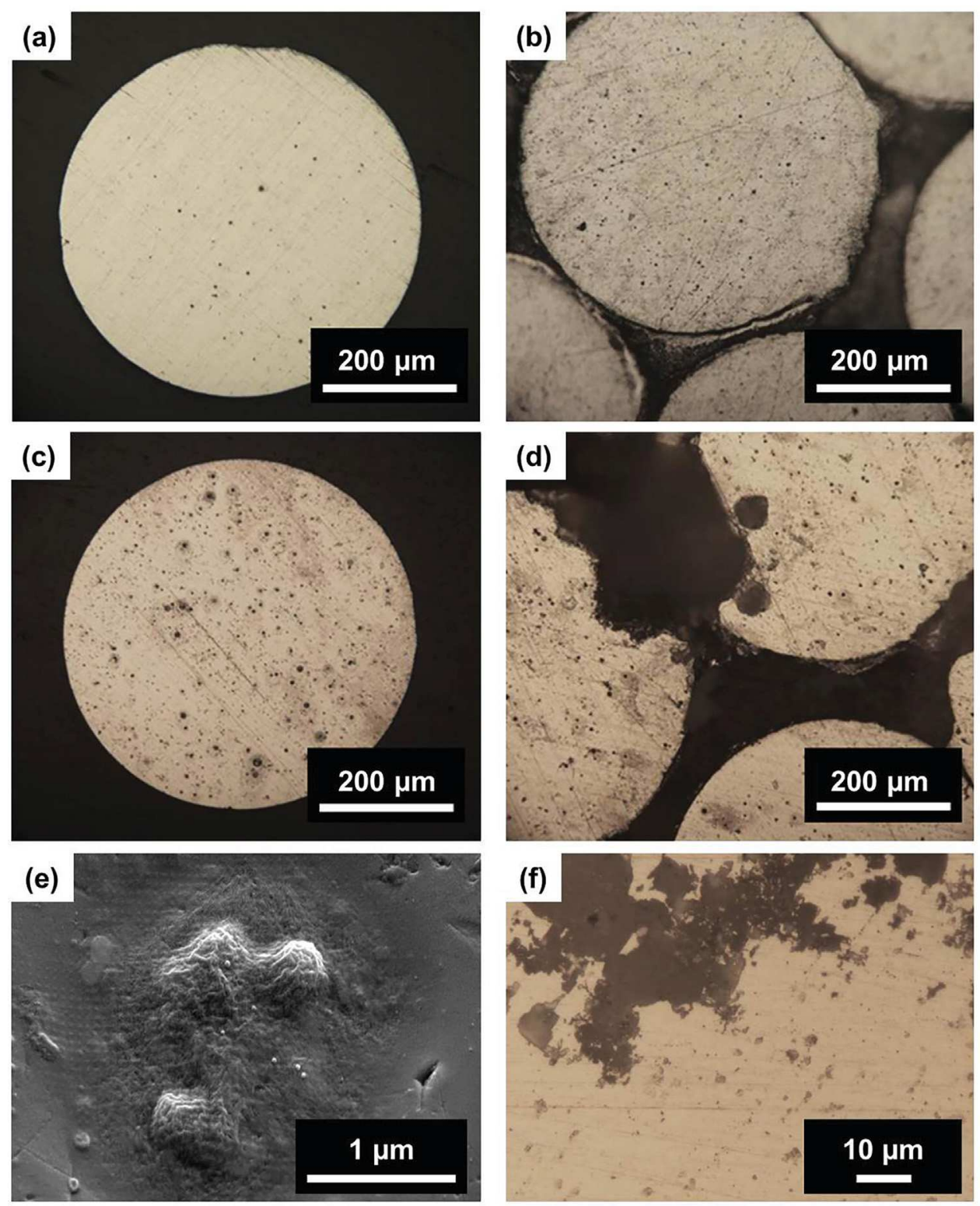

Fig. 2. Optical microscope (OM) observations of the strand and of the cable after: (a, b) $3 \mathrm{~h}$ of immersion and (c, d) $168 \mathrm{~h}$ of immersion at $\mathrm{E}_{\text {corr }}$ in $0.1 \mathrm{M} \mathrm{Na} \mathrm{SO}_{4}+0.001 \mathrm{M} \mathrm{NaCl}$.

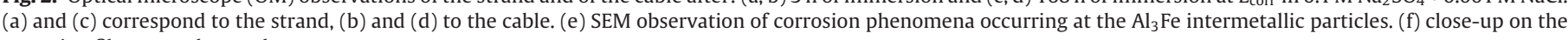
corrosion filaments observed.

b showed that after $3 \mathrm{~h}$ the matrix dissolution around the intermetallic particles was more extended for the cable than for the strand. After $168 \mathrm{~h}$ of immersion (Fig. 2c and d), a significant dissolution of the matrix around the Fe-rich particles (Fig. 2e) can be seen on the whole surface for both samples, and in addition, for the cable, large pits surrounded by fine filaments (Fig. 2f) were also observed at the periphery of the strands. These corrosion features, in agreement with literature data, accounted for the penetration of the electrolyte inside the cable leading to a confined medium and crevice corrosion phenomenon [10,11]. OM observations of cross-sections parallel to the cable axis after various exposure times to the chloride-containing sulphate solution corroborated this assumption and allowed the depth of the corroded zone to be measured (Fig. 3a). It was assumed to be a good indication of the electrolyte penetration depth. In order to measure the depth of the corroded zone, the corrosion damage was enhanced by polarizing at $-700 \mathrm{mV} / \mathrm{SCE}$ for $5 \mathrm{~min}$ the samples after the exposure at $\mathrm{E}_{\mathrm{corr}}$ (Fig. 3a and $\mathrm{b}$ ). The electrolyte penetration depth was found to become rapidly independent of the exposure time, reaching about $800 \mu \mathrm{m}$ after $3 \mathrm{~h}$ of exposure (Fig. 3c).

Fig. 4 reports $E_{\text {corr }}$ values versus exposure time to the electrolyte for the strand sample and the cable. For the strand sample, $\mathrm{E}_{\text {corr }}$ stabilized rapidly and an almost stationary value (around $-600 \mathrm{mV} / \mathrm{SCE}$ ) was obtained after $3 \mathrm{~h}$ of immersion. On the contrary, for the cable, $\mathrm{E}_{\text {corr }}$ decreased significantly towards more negative values during immersion which was in agreement with the differences in corrosion morphology observed between the two samples (Fig. 2). Fig. 5 shows the polarization curves for the strand sample and the cable obtained after $3 \mathrm{~h}$ of exposure to the chloridecontaining sulphate solution. For the cable, the current densities were calculated by taking into account (i) only the cross-sections of the 50 strands constitutive of the cable, i.e. only the surface exposed to the bulk solution $\left(S=0.11 \mathrm{~cm}^{2}\right.$, no corrected surface in Fig. 5) and (ii) both the cross-sections and the lateral surface of the 50 strands on a $800 \mu \mathrm{m}$ depth, i.e. both the surfaces exposed to the bulk and to a confined electrolyte $\left(S=0.76 \mathrm{~cm}^{2}\right.$, corrected 
(a) insulating cable surface exposed to the insulating
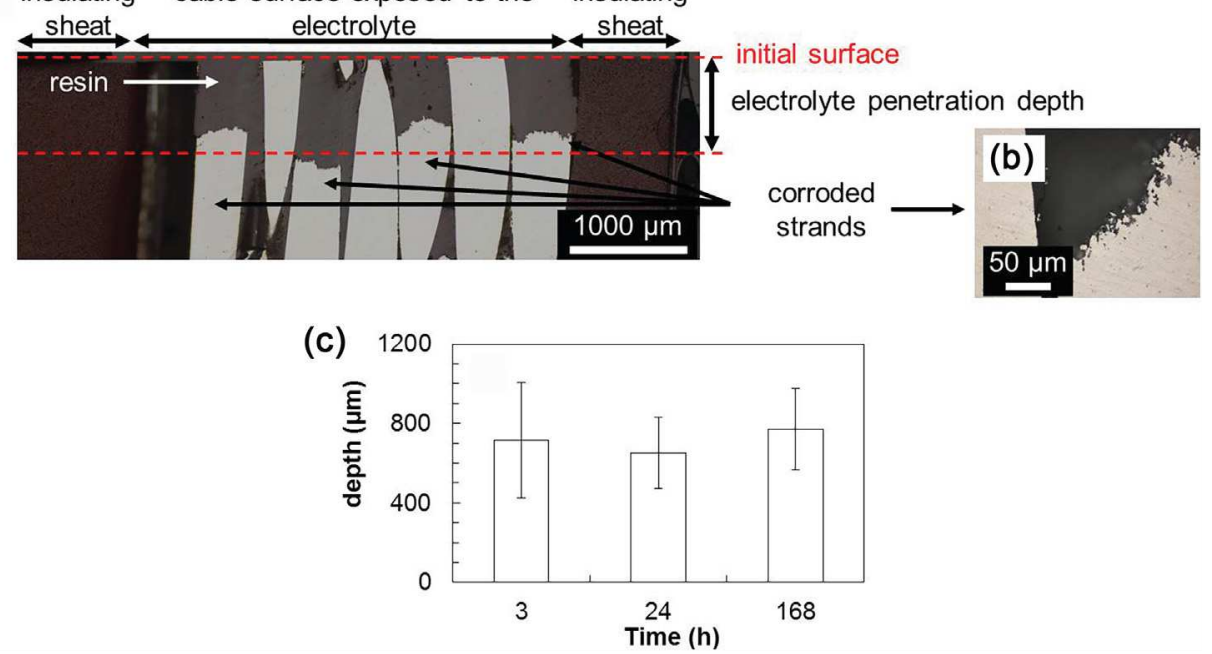

Fig. 3. (a) OM observation of a cable cross-section (parallel to the cable axis) after $3 \mathrm{~h}$ of exposure to the $0.1 \mathrm{M} \mathrm{Na}_{2} \mathrm{SO}_{4}+0.001 \mathrm{M} \mathrm{NaCl}$ solution followed by polarization for $5 \mathrm{~min}$ at $-700 \mathrm{mV} / \mathrm{SCE}$; (b) close-up on a corroded strand inside the cable; (c) electrolyte penetration depth versus the exposure time.

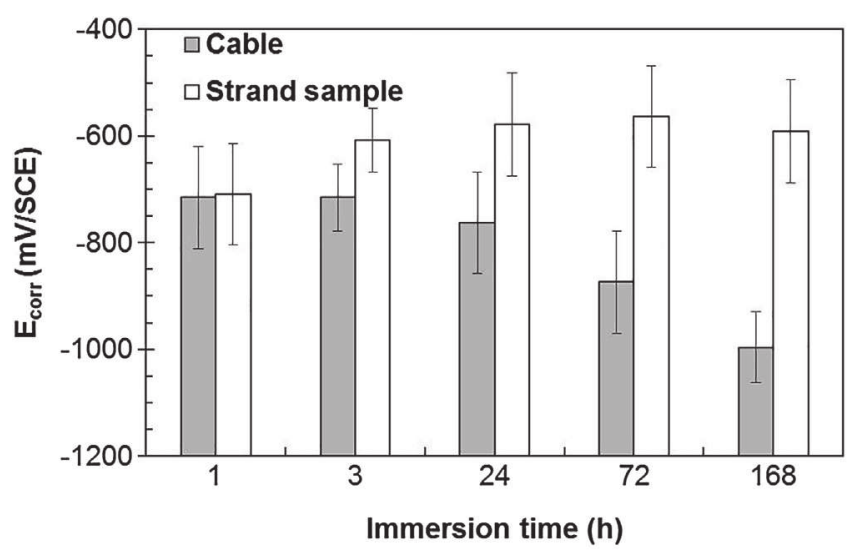

Fig. 4. Variation of $\mathrm{E}_{\text {corr }}$ during immersion in $0.1 \mathrm{M} \mathrm{Na}_{2} \mathrm{SO}_{4}+0.001 \mathrm{M} \mathrm{NaCl}$ for the strand sample and the cable.

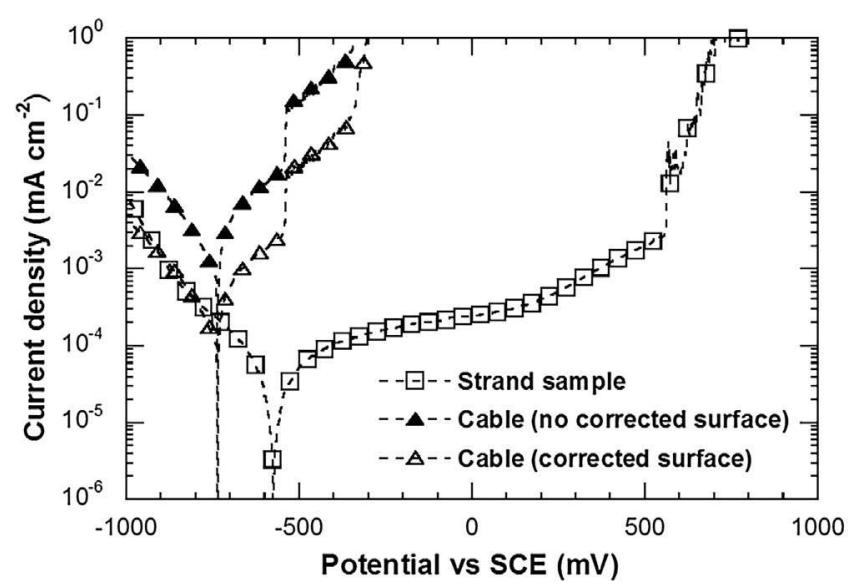

Fig. 5. Polarization curves of the strand sample and the cable obtained after $3 \mathrm{~h}$ of immersion at $\mathrm{E}_{\text {corr }}$ in $0.1 \mathrm{M} \mathrm{Na}_{2} \mathrm{SO}_{4}+0.001 \mathrm{M} \mathrm{NaCl}$. Scan rate $=0.07 \mathrm{mV} \mathrm{s}^{-1}$. For the cable, the curve 'no corrected surface' only takes into account the cable surface exposed to the bulk $\left(\mathrm{S}=0.11 \mathrm{~cm}^{2}\right)$; the 'corrected surface' curve takes into account both the surface exposed to the bulk and that exposed to the confined medium inside the cavities $\left(S=0.76 \mathrm{~cm}^{2}\right)$. surface in Fig. 5). For both the strand sample and the cable, the cathodic branch, corresponding mainly to the oxygen reduction, was similar. For the strand sample and the cable, $\mathrm{E}_{\text {corr }}$ values were $-580 \mathrm{mV} / \mathrm{SCE}$ and $-730 \mathrm{mV} / \mathrm{SCE}$ respectively. The anodic domain was characterized for the strand sample by a passivity plateau, with passive current densities of about $4.10^{-4} \mathrm{mAcm}^{-2}$, followed by a breakdown potential at $500 \mathrm{mV} / \mathrm{SCE}$ associated with, first, a slow increase of the anodic current densities and then a sharper one. This could be associated to, first, an increase of the dissolution rate of the matrix surrounding the Fe-rich particles and then to pitting corrosion. Besides, the significant current fluctuations observed after the sharp increase of the current densities constitutes a characteristic feature of the pitting corrosion. For the cable, a short pseudo-plateau was observed and the anodic current densities were about $2.10^{-3} \mathrm{~mA} \mathrm{~cm}^{-2}$ (corrected surface). Whatever the surface taken into account, the current densities were higher for the cable, as compared to the strand sample; this could be assigned to a dissolution process rather than a passivity process. A breakdown potential was then observed at $-550 \mathrm{mV} / \mathrm{SCE}$ followed by a sharp increase of the anodic current densities. All the results showed a lower corrosion resistance for the cable as compared to the strand sample. The differences in corrosion behaviour between the two samples were related to the penetration of the electrolyte inside the cable cavities leading to the formation of a confined and then more aggressive electrolyte. This confirmed, for the cable, the occurrence of both pitting corrosion on the surface exposed to the bulk solution and crevice corrosion on the surface exposed to the confined medium inside the cavities. The higher anodic current densities observed for the cable were related to the progressive modification of the electrolyte trapped inside the cavities and subsequent dissolution phenomenon.

Impedance measurements were performed for the strand sample and the cable after different exposure times to the chloridecontaining sulphate solution. Fig. 6 shows the diagrams in Bode (Fig. 6a) and Nyquist (Fig. 6b) coordinates for the strand sample. After $3 \mathrm{~h}$ and $24 \mathrm{~h}$ of immersion, the impedance diagrams are characterized by two time constants. The first time constant $(60 \mathrm{kHz}-1 \mathrm{~Hz})$ was associated to the response of the passive film, while the second time constant $(1 \mathrm{~Hz}-100 \mathrm{mHz})$ was attributed to the charge transfer process and to the oxygen reduction on the passive film in agreement with literature [27]. Impedance measurements performed at $\mathrm{E}_{\mathrm{corr}}$ in a deaerated electrolyte (results not shown) revealed the disappearance of the time constant observed 

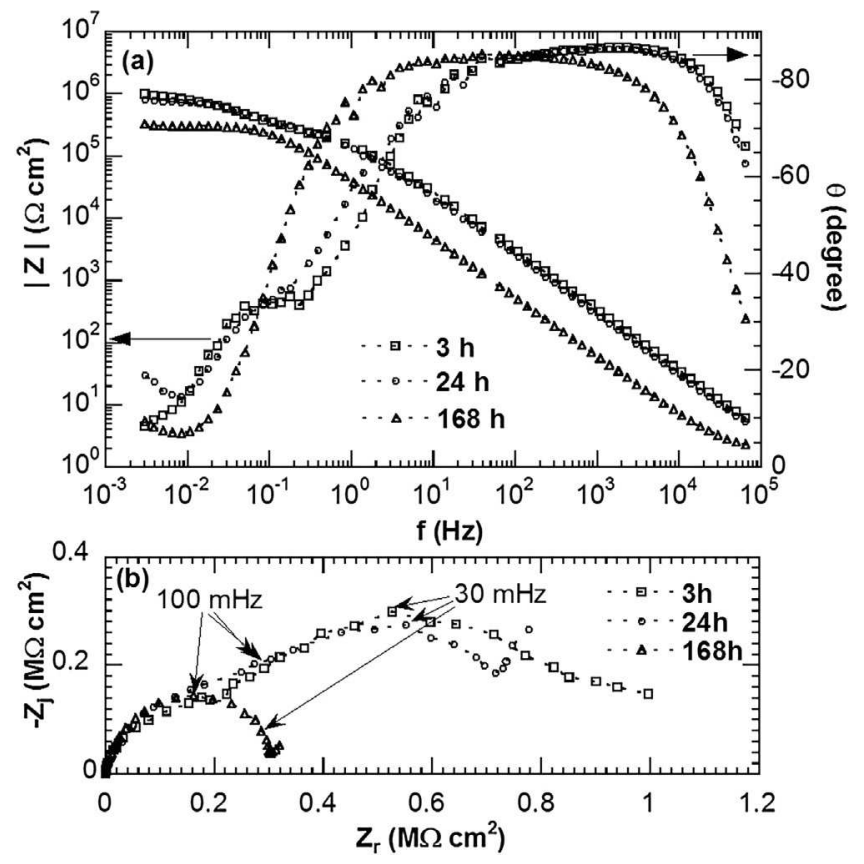

Fig. 6. Electrochemical impedance diagrams obtained for the strand sample - (a) Bode and (b) Nyquist coordinates - after different exposure times at $\mathrm{E}_{\text {corr }}$ to $0.1 \mathrm{M}$ $\mathrm{Na}_{2} \mathrm{SO}_{4}+0.001 \mathrm{M} \mathrm{NaCl}$.

at low frequencies and no modification in the high frequency domain. This confirmed the attribution of the low frequency time constant to the oxygen reduction. After $168 \mathrm{~h}$ of immersion, the impedance diagram showed only one time constant with a lower resistance which could be associated to the corrosion of the alloy, i.e. to the charge transfer process. Such an evolution of the diagrams was in agreement with the OM observations (Fig. 2c), i.e. the dissolution of the matrix surrounding the Fe-rich particles due to oxygen reduction on the intermetallics and subsequent alcalinization of the electrolyte for increasing immersion times. The impedance diagrams obtained for the cable (Fig. 7) were clearly modified as compared to those obtained for the strand sample. The results are presented by taking into account the total surface exposed to the electrolyte (the surface exposed to the bulk solution and that exposed to the confined medium trapped inside the cavities). The Nyquist diagram (Fig. 7b) was constituted by a straight line in the high-frequency domain followed by a semicircle. This typical shape can be associated to the oxygen diffusion in a porous system [30-33] in agreement with the penetration of the electrolyte inside the cable cavities. The flattened semicircle may originate from the cavity shape [34]. The impedance values for the cable were ten times smaller than those obtained for the strand sample in agreement with the differences in corrosion damage between the two samples which highlighted the influence of the electrolyte penetration through the cavities of the cable. For $168 \mathrm{~h}$ of immersion, a decrease of the impedance was observed and, in the high-frequency domain, a time constant appeared which could be associated to the corrosion of the alloy in the confined medium [35,36]. Additional experiments (results not shown) were performed with a crosssection of the cable for which the cavities had been sealed with a resin by forcing the resin to penetrate into the cavities with a vacuum system. The impedance diagram obtained for the cable with sealed cavities after immersion in the aggressive solution and that of the strand sample were superimposed. This was in agreement with comments in the experimental part and confirmed that the corrosion behaviour of the cable was controlled by the penetration of the electrolyte inside the cable.
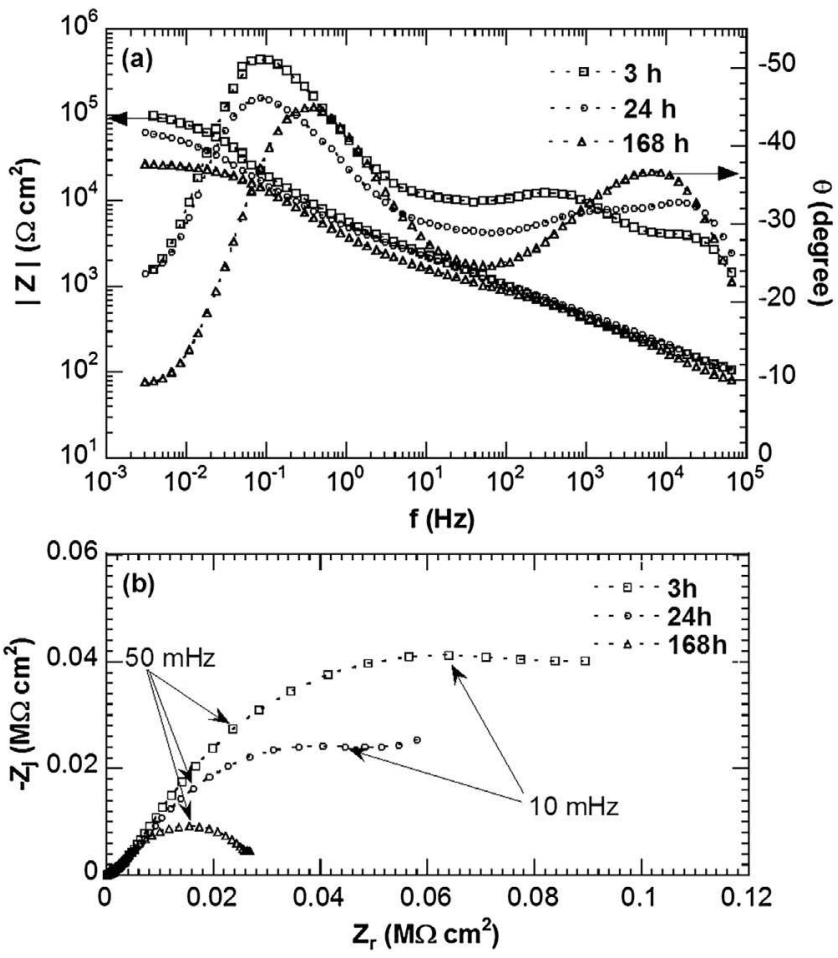

Fig. 7. Electrochemical impedance diagrams obtained for the cable - (a) Bode and (b) Nyquist coordinates - after different exposure times at $\mathrm{E}_{\text {corr }}$ to $0.1 \mathrm{M}$ $\mathrm{Na}_{2} \mathrm{SO}_{4}+0.001 \mathrm{M} \mathrm{NaCl}$. The impedance values take into account both the surface exposed to the bulk and that exposed to the confined medium inside the cavities $\left(\mathrm{S}=0.76 \mathrm{~cm}^{2}\right)$

Equivalent electrical circuits are frequently used to extract parameters associated with the impedance diagrams. In the present study, the different sets of impedance measurements performed allowed the interpretation of the different time constants in agreement with literature data and relevant parameters were defined. For the strand sample, relevant parameters were the oxide film resistance $\left(R_{O X}\right)$ and the charge transfer resistance $\left(R_{t}\right)$. They were directly measured on the impedance spectra. Further, among relevant parameters, a constant phase element (CPE) is often used instead of a capacitance to take the non-ideal behaviour of the interface into account. The CPE is given by:

$Z_{C P E}=\frac{1}{Q(j \omega)^{\alpha}}$

where $\alpha$ is related to the angle of rotation of a purely capacitive line on the complex plane plots and $Q$ is in $\Omega^{-1} \mathrm{~cm}^{-2} \mathrm{~s}^{\alpha}$. In the present study, $\alpha$ and $Q$ were determined using the graphical method proposed by Orazem et al. [37]. For the cable, considering the complexity of a porous system, the polarization resistance $\left(R_{p}\right)$ was assumed to allow the corrosion resistance of the cable to be compared to that of the strand sample. Fig. 7a showed that the impedance modulus was quite stable for frequencies lower than $10 \mathrm{mHz}$; therefore, the impedance at low frequency $(3 \mathrm{mHz})$ was measured and used to evaluate the corrosion resistance of the cable. The impedance parameters are reported in Table 1.

For the strand sample, during the first $24 \mathrm{~h}$ of immersion, $\alpha_{\mathrm{ox}}$ remained constant and equal to 0.95 . The values of $\mathrm{Q}_{\mathrm{ox}}$ slightly increased from $7.310^{-7} \Omega^{-1} \mathrm{~cm}^{-2} \mathrm{~s}^{0.95}$ to $8.610^{-7} \Omega^{-1} \mathrm{~cm}^{-2} \mathrm{~s}^{0.95}$. The $\alpha_{\mathrm{ox}}$ and $\mathrm{Q}_{\mathrm{ox}}$ values accounted for the presence of a passive layer. The variation of $\mathrm{Q}_{\mathrm{ox}}$ with increasing immersion time could be related to the evolution of the thickness and/or of the chemical composition of the passive film in relation with the dissolution of the matrix around the intermetallics. During the first $24 \mathrm{~h}$, the 
Table 1

Parameters obtained from the impedance diagrams for the strand sample and for the cable after different immersion times in $0.1 \mathrm{M} \mathrm{Na}_{2} \mathrm{SO}_{4}+0.001 \mathrm{M} \mathrm{NaCl}$ solution. For the cable, the impedance values take into account both the surface exposed to the bulk and that exposed to the confined medium inside the cavities $\left(\mathrm{S}=0.76 \mathrm{~cm}{ }^{2}\right)$.

\begin{tabular}{|c|c|c|c|c|}
\hline & & \multicolumn{3}{|c|}{ Immersion Times (h) } \\
\hline & & 3 & 24 & 168 \\
\hline Strand & $\begin{array}{l}\mathrm{R}_{\mathrm{ox}}\left(\mathrm{k} \Omega \mathrm{cm}^{2}\right) \\
\alpha_{\mathrm{ox}} \\
\mathrm{Q}_{\mathrm{ox}}\left(\Omega^{-1} \mathrm{~cm}^{-2}\right) \mathrm{s}^{\alpha} \\
\mathrm{R}_{\mathrm{t}}\left(\mathrm{k} \Omega \mathrm{cm}^{2}\right) \\
\alpha \\
\mathrm{Q}\left(\Omega^{-1} \mathrm{~cm}^{-2}\right) \mathrm{s}^{\alpha}\end{array}$ & $\begin{array}{l}201 \pm 5 \\
0.95 \pm 0.01 \\
7.310^{-7} \pm 110^{-7} \\
1010 \pm 20 \\
/\end{array}$ & $\begin{array}{l}220 \pm 5 \\
0.95 \pm 0.01 \\
8.610^{-7} \pm 110^{-7} \\
821 \pm 10 \\
/ \\
/\end{array}$ & $\begin{array}{l}\text { I } \\
/ \\
/ \\
324 \pm 5 \\
0.94 \pm 0.01 \\
4.2510^{-6} \pm 110^{-6}\end{array}$ \\
\hline Cable & $\mathrm{R}_{\mathrm{p}}\left(\mathrm{k} \Omega \mathrm{cm}^{2}\right)$ & $106 \pm 5$ & $63 \pm 5$ & $27 \pm 2$ \\
\hline
\end{tabular}

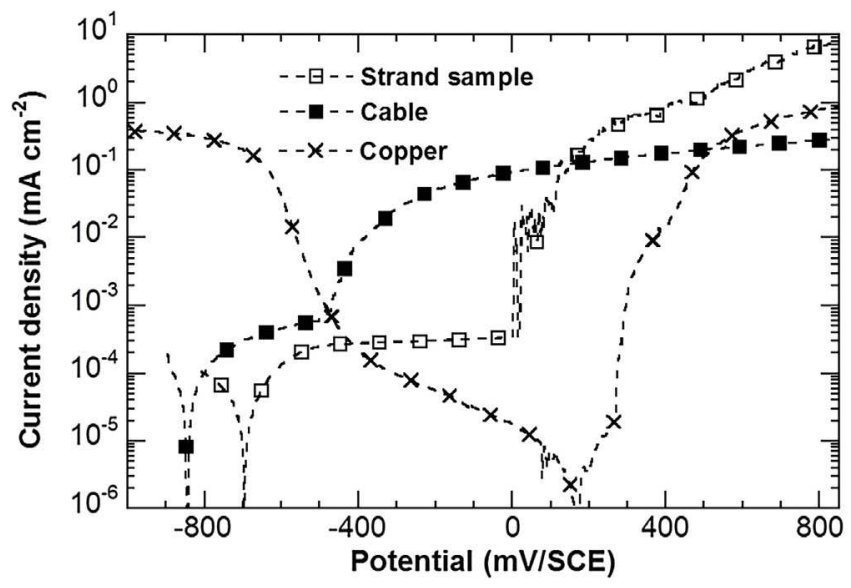

Fig. 8. Polarization curves of the AA1370 strand sample, the AA1370 cable and the pure $\mathrm{Cu}$ connector after $3 \mathrm{~h}$ of immersion at $\mathrm{E}_{\mathrm{corr}}$ in $0.001 \mathrm{M} \mathrm{NaCl}$ solution.

corrosion behaviour of the strand sample was controlled by the presence of the oxide film with high values of both $R_{0 x}$ and $R_{t}$ while, for $168 \mathrm{~h}$ of immersion, the electrochemical behaviour was controlled by the corrosion processes (decrease of the $\mathrm{R}_{\mathrm{t}}$ values). For the cable, the low $R_{p}$ values were in agreement with the low corrosion resistance of the cable as compared to the strand sample; moreover, the decrease of $\mathrm{R}_{\mathrm{p}}$ with increasing immersion time was in agreement with the extent of the corrosion damage related to the penetration of the electrolyte inside the cable and to the crevice corrosion phenomena on the surface exposed to the confined medium while pitting occurred on the surface exposed to the bulk.

\subsection{Electrochemical behaviour of the assembly}

\subsubsection{Preliminary experiments and observations}

A preliminary study was performed in $0.001 \mathrm{M} \mathrm{NaCl}$ to characterize separately the corrosion behaviour of $\mathrm{Al}$ (i.e. AA1370) and $\mathrm{Cu}$ in the same solution as that used for the LEIS measurements. First, the anodic branch of the polarization curves for the Al samples (strand sample and cable) and the cathodic and anodic branches for pure $\mathrm{Cu}$ were obtained (Fig. 8). Comparison of Figs. 5 and 8 showed that the global shape of the curves for the Al samples was the same independently of the electrolyte. For the strand sample, a $600 \mathrm{mV}$-long plateau corresponding to a passivity plateau with low anodic current densities $\left(3.10^{-4} \mathrm{~mA} \mathrm{~cm}^{-2}\right)$ was observed and followed by an abrupt increase of the current associated to pitting corrosion. For the cable, a plateau was also observed; it was better defined than in sulphate and chloride-containing solutions but, again, corresponded to higher anodic current densities than for the strand sample and was considered as a pseudo-passivity plateau. It was rapidly followed by a sharp increase of the anodic current densities associated to both pitting and crevice corrosion as previ-

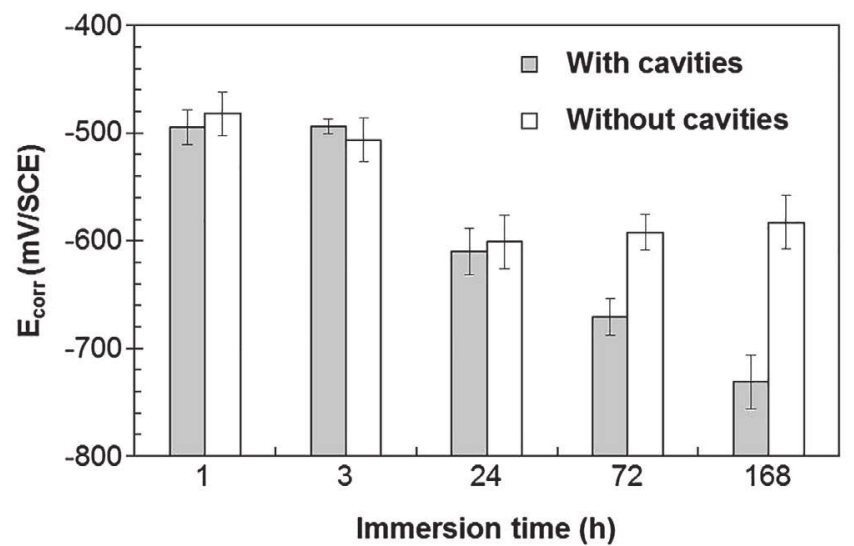

Fig. 9. Variation of $\mathrm{E}_{\text {corr }}$ during immersion in $0.001 \mathrm{M} \mathrm{NaCl}$ solution for the $\mathrm{Al} / \mathrm{Cu}$ assemblies with and without cavities.

ously explained. As observed in the chloride-containing sulphate solution, the breakdown potential associated to the increase of the anodic current densities was more negative for the cable (pitting and crevice corrosion) than for the strand sample (pitting corrosion) which showed the lower corrosion resistance of the cable as compared to the strand sample. In the $0.001 \mathrm{M} \mathrm{NaCl}$ solution, the breakdown potential was $10 \mathrm{mV} / \mathrm{SCE}$ and $-500 \mathrm{mV} / \mathrm{SCE}$ for the strand sample and the cable, respectively. Then, it can be seen from Fig. 8 that the corrosion potential of pure $\mathrm{Cu}$ was more positive $(200 \mathrm{mV} / \mathrm{SCE})$ than those of the strand sample $(-700 \mathrm{mV} / \mathrm{SCE})$ and the cable $(-850 \mathrm{mV} / \mathrm{SCE})$ showing as expected that, in the $\mathrm{Al} / \mathrm{Cu}$ assembly, pure $\mathrm{Cu}$ will be the cathode and the Al samples will be the anode [20,21,38-40]. From the anodic curves of the $\mathrm{Al}$ samples and the cathodic curve of $\mathrm{Cu}$, the common potential measured, in the case of a galvanic coupling between the two metals with the same surface area, would be about $-400 \mathrm{mV} / \mathrm{SCE}$ for an $\mathrm{Al}$ strand sample/Cu assembly, and $-500 \mathrm{mV} / \mathrm{SCE}$ for an $\mathrm{Al}$ cable/Cu assembly. It was worth noticing that, for the assemblies investigated here and as shown in Fig. 1, the ratio $\mathrm{S}_{\mathrm{Cu}} / \mathrm{S}_{\mathrm{Al}}\left(\mathrm{S}_{\mathrm{Cu}}\right.$ and $\mathrm{S}_{\mathrm{Al}}$ are the surface areas exposed to the electrolyte in the assembly respectively for $\mathrm{Cu}$ and $\mathrm{Al}$ ) was significantly higher than 1 . Therefore, the common potential should be shifted towards more positive values than those previously estimated (with the same surface area). From Fig. 8, it can be clearly seen that, in $0.001 \mathrm{M} \mathrm{NaCl}$, the common potential was in the localized corrosion (pitting and crevice corrosion) regime for the cable, whereas, depending on the ratio $\mathrm{S}_{\mathrm{Cu}} / \mathrm{S}_{\mathrm{Al}}$, it could be in the passive regime for the strand sample. This meant that a severe corrosion damage was expected for the cable when coupled with $\mathrm{Cu}$. This suggested also that differences should be observed between the two types of assembly, i.e. with and without (all the strands constitutive of the cable being welded together) cavities, as described in Fig. 1. 

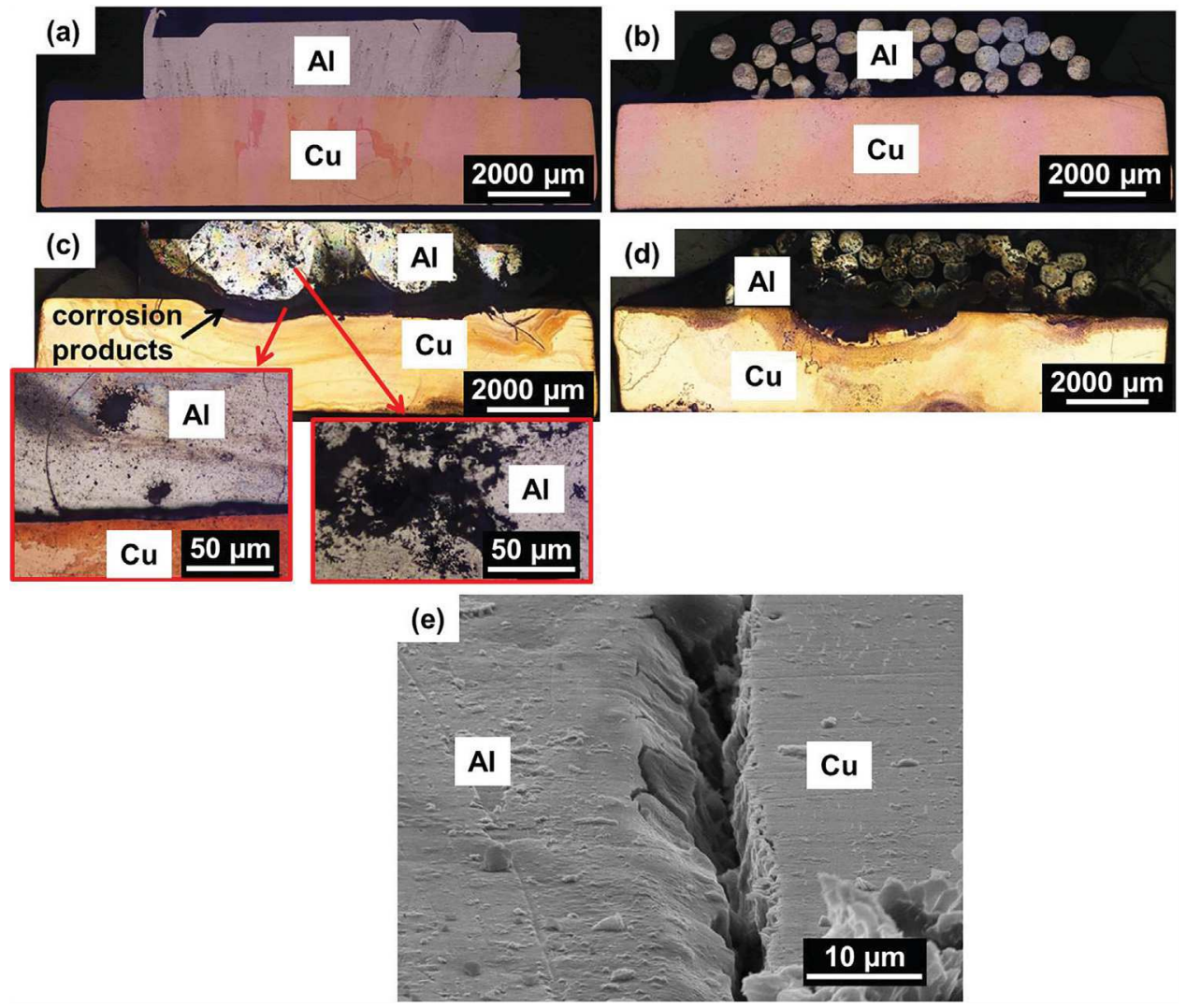

Fig. 10. Optical microscope observations of the corrosion damage for the $\mathrm{Al} / \mathrm{Cu}$ assemblies after (a, b) $3 \mathrm{~h}$ and (c, d) $168 \mathrm{~h}$ of immersion at $\mathrm{E}_{\text {corr }}$ in a $0.001 \mathrm{M} \mathrm{NaCl}$ solution: assembly (a, c) without and (b, d) with cavities. (e) SEM micrograph of the $\mathrm{Al} / \mathrm{Cu}$ interface of the assembly without cavities after $24 \mathrm{~h}$ of immersion in $0.001 \mathrm{M}$ NaCl solution (tilt of $70^{\circ}$ ).

Fig. 9 showed $\mathrm{E}_{\text {corr }}$ values versus immersion time in $0.001 \mathrm{M}$ $\mathrm{NaCl}$ for the two types of assembly. As expected, $\mathrm{E}_{\text {corr }}$ values were between those of the $\mathrm{Al}$ cable and $\mathrm{Cu}$. For both assemblies, $\mathrm{E}_{\text {corr }}$ values decreased with increasing immersion time which could be related to corrosion damage. During the first $24 \mathrm{~h}$, $\mathrm{E}_{\text {corr }}$ values were the same for the two types of assembly; they decreased slowly from $-500 \mathrm{mV} / \mathrm{SCE}$ to $-600 \mathrm{mV} / \mathrm{SCE}$. After $24 \mathrm{~h}$ of immersion, $\mathrm{E}_{\text {corr }}$ of the assembly without cavities stabilized around $-600 \mathrm{mV} / \mathrm{SCE}$, whereas, for the assembly with cavities, $\mathrm{E}_{\mathrm{corr}}$ moved towards more negative values and reached $-770 \mathrm{mV} / \mathrm{SCE}$ after $168 \mathrm{~h}$ of immersion. This variation of $\mathrm{E}_{\mathrm{corr}}$ suggested that, for an immersion time longer than $24 \mathrm{~h}$, the corrosion damage was more extended for the assembly with cavities and underlined, as already discussed, that the presence of cavities in the cable modified the corrosion processes.

The corrosion damages for the two types of assembly were observed by OM and SEM after short immersion times ( $3 \mathrm{~h}$ and $24 \mathrm{~h}$ ) and long immersion time (168 h) in $0.001 \mathrm{M} \mathrm{NaCl}$ (Fig. 10; results are only given for $3 \mathrm{~h}$ and $168 \mathrm{~h}$ ). Independently of the immersion time, Al part was corroded while the $\mathrm{Cu}$ surface exposed to the bulk solution remained safe. For a short immersion time, no significant difference was observed between the two types of assembly (Fig. 10a and b). After $168 \mathrm{~h}$ of immersion, significant differences were observed for the Al part depending on the presence or not of cavities (Fig. 10c and d). For the assembly without cavities, OM observations showed the presence of pits and numerous fine filaments around the pits for the Al part (Fig. 10c). For the assembly with cavities, a severe corrosion damage of the Al part was observed with not only pits observed on the surface exposed to the bulk solution but also some strands constitutive of the cable completely dissolved over several hundreds of micrometers in depth. These corrosion features were in agreement with pitting corrosion phenomena occurring on the surface exposed to the bulk solution while crevice corrosion occurred in the cavities [38]. More detailed attention was paid to the $\mathrm{Al}-\mathrm{Cu}$ interface. For both assemblies, corrosion products (black areas in Fig. 10c and d) were clearly observed at the $\mathrm{Al} / \mathrm{Cu}$ interface and spread all over the $\mathrm{Al}$ part for the assembly with cavities (Fig. 10d). Fig. 10e shows a SEM micrograph of the $\mathrm{Al} / \mathrm{Cu}$ interface after $24 \mathrm{~h}$ of immersion for the assembly without cavities. At the $\mathrm{Al} / \mathrm{Cu}$ interface, a crevice was clearly visible and also the Al dissolution. Such a crevice was also observed for the assembly with cavities: it was even more visible. Similar feature was already observed for a $\mathrm{Al} / \mathrm{Cu}$ model couple [19]. This showed that for $\mathrm{Cu}$, even though no corrosion damage was observed on the surface exposed to the bulk solution, corrosion phenomena occurred on the vertical wall inside the crevice, referring to crevice corrosion processes $[20,21]$. Thus, for both assemblies, the initial step of the corrosion process was the dissolution of the $\mathrm{Al}$ part at the $\mathrm{Al} / \mathrm{Cu}$ interface due to the alkalinisation linked to the oxygen reduction reaction on the $\mathrm{Cu}$ part [19]. The electrochemical reactions that justify the aluminium corrosion were as follows [38,40-42]:

Cathodic (on the Cu surface exposed to the bulk solution):

$\mathrm{O}_{2}+2 \mathrm{H}_{2} \mathrm{O}+4 \mathrm{e}^{-} \rightarrow 4 \mathrm{OH}^{-}$

Anodic:

$$
\begin{aligned}
& \mathrm{Al} \rightarrow \mathrm{Al}^{3+}+3 \mathrm{e}^{-} \\
& 2 \mathrm{Al}+6 \mathrm{H}_{2} \mathrm{O} \rightarrow 2 \mathrm{Al}(\mathrm{OH})_{3}+3 \mathrm{H}_{2} \\
& \mathrm{Al}(\mathrm{OH})_{3}+\mathrm{OH}^{-} \rightarrow\left[\mathrm{Al}(\mathrm{OH})_{4}\right]^{-}
\end{aligned}
$$

With increasing immersion time, in the crevice, hydrolysis of cations can be assumed and as a consequence the chemical 

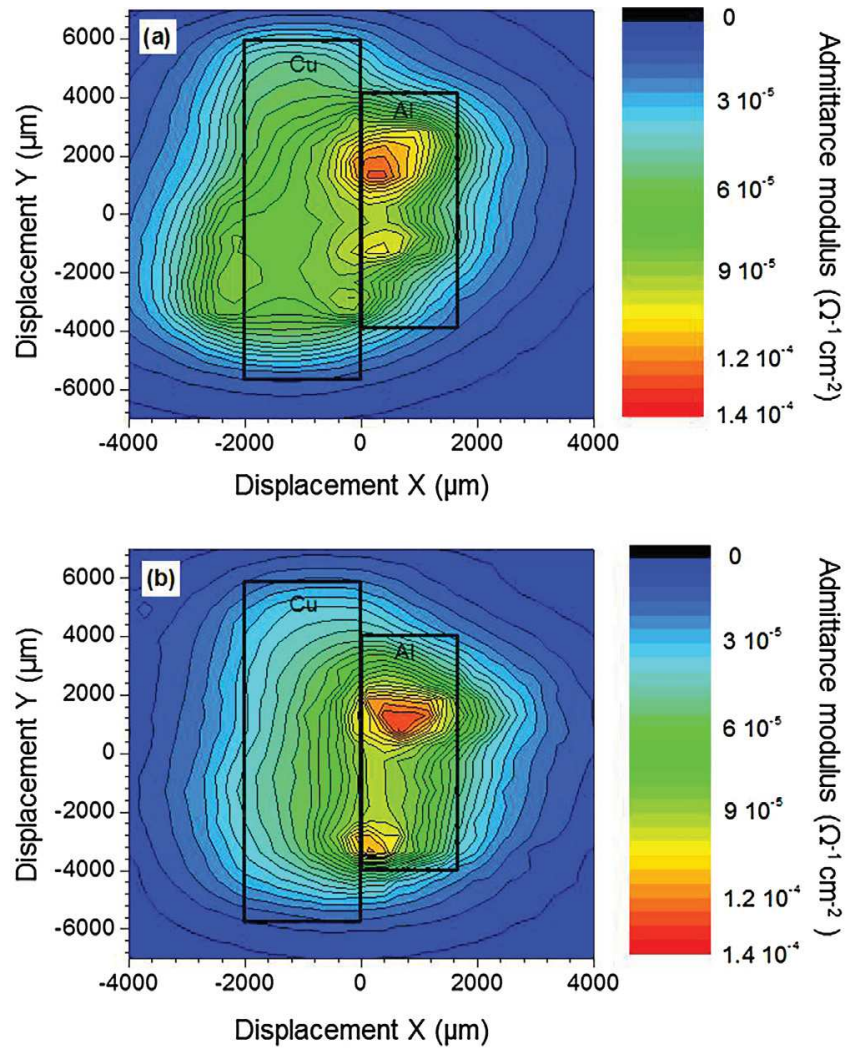

Fig. 11. Admittance maps obtained after $24 \mathrm{~h}$ of immersion at $\mathrm{E}_{\text {corr }}$ in $0.001 \mathrm{M} \mathrm{NaCl}$ solution at $10 \mathrm{~Hz}$ above the $\mathrm{Al} / \mathrm{Cu}$ assemblies: (a) without cavities and (b) with cavities. Admittance values are calculated taking into account an analyzed surface of $1 \mathrm{~mm}^{2}$.

composition of the electrolyte at the $\mathrm{Al} / \mathrm{Cu}$ interface should vary significantly with a decrease of $\mathrm{pH}$ as shown by Shi et al. [40]. This can be ascribed to the reaction of Al dissolution and hydrolysis [40]:

$\mathrm{Al}+\mathrm{nH}_{2} \mathrm{O} \rightarrow \mathrm{Al}(\mathrm{OH})_{\mathrm{n}}{ }^{3-\mathrm{n}}+\mathrm{nH}^{+}+3 \mathrm{e}^{-}, \mathrm{n}=1-3$

Therefore, in the crevice formed at the $\mathrm{Al} / \mathrm{Cu}$ interface, the $\mathrm{pH}$ got more acidic which should promote a crevice corrosion phenomenon for $\mathrm{Cu}$. On the opposite, far from the $\mathrm{Al} / \mathrm{Cu}$ interface, $\mathrm{Cu}$ was in contact with the bulk solution where oxygen is present [21] leading to a non-corroded surface. For the Al part, for the assembly without cavities, pitting corrosion was observed. Concerning the assembly with cavities, pitting corrosion was observed on the Al surface exposed to the bulk solution and crevice corrosion occurred in the cavities existing between the strands due to the penetration of the electrolyte inside the cavities. Therefore, the corrosion products observed should include both copper oxides, aluminium oxides and hydroxides $[20,38,40,42]$. Håkansson et al. showed that the main corrosion products formed during galvanic corrosion of aluminium/carbon systems in $0.6 \mathrm{M} \mathrm{NaCl}$ was $\mathrm{Al}(\mathrm{OH})_{3}$, presented as a gelatinous substance in the crevices between the Al wires [43]. These authors also showed that $\mathrm{Al}(\mathrm{OH})_{3}$ should control the rate of the corrosion processes which should explain the plateau observed on the polarization curves for the cable after the breakdown potential (Fig. 8).

\subsubsection{LEIS study of the assemblies}

LEIS was first used in mapping mode. Maps obtained at $10 \mathrm{~Hz}$ for the assemblies with and without cavities, after $24 \mathrm{~h}$ of exposure in a $0.001 \mathrm{M} \mathrm{NaCl}$ solution are shown in Fig. 11. For both samples, the admittance values are higher (i.e., lower resistance) on the Al part which was due to the galvanic coupling between $\mathrm{Al}$ (anode) and $\mathrm{Cu}$ (cathode). Moreover, heterogeneous values of the admittance were observed on the Al part in accordance with pitting corrosion processes, as previously shown. Comparison of Fig. 11a and b did not show significant differences between the two types of assembly in agreement with $\mathrm{E}_{\text {corr }}$ measurements (Fig. 9).

Then, local impedance spectra were collected after $24 \mathrm{~h}$ and $168 \mathrm{~h}$ of immersion for the two types of assembly (Fig. 12, Nyquist coordinates).

First, it can be seen that impedance values on the $\mathrm{Al}$ part for the assembly with cavities are higher than those for the assembly without cavities. As explained in the experimental part, impedance values on the Al part are overestimated for the assembly with cavities. The error on the measurements was estimated to be about $20 \%$ by considering only the surface exposed to the bulk solution. If the surface exposed to the confined electrolyte in the cavities (considering the surface in the plane parallel to the cable axis) is taken into account, this error should be reduced because the exposed surface would be increased. Nevertheless, despite these inaccurate measurements, it was helpful, for both $\mathrm{Al} / \mathrm{Cu}$ assemblies, to study the changes observed for the local impedance diagrams versus immersion time and to compare the electrochemical response of the $\mathrm{Al}$ part and the $\mathrm{Cu}$ part to describe the influence of the cavities on the corrosion behaviour of the $\mathrm{Al} / \mathrm{Cu}$ assembly.

Then, for both assemblies, the impedance values after $24 \mathrm{~h}$ of immersion (Fig. 12a and b) were higher on the $\mathrm{Cu}$ part, then decreased when the probe moved towards the $\mathrm{Al} / \mathrm{Cu}$ interface, and decreased again when the probe was over the Al part. Such an evolution of the impedance as a function of the position of the probe was in agreement with the galvanic coupling between $\mathrm{Al}$ and $\mathrm{Cu}$. After $24 \mathrm{~h}$ of immersion, pitting corrosion occurred on the Al part (Fig. 10). For the assembly with cavities, the diagrams plotted for the $\mathrm{Cu}$ part (red curves in Fig. 12) are significantly modified in the low frequency range as compared to those obtained for the assembly without cavities. Their global shape suggested a diffusioncontrolled electrochemical process in relation with the cathodic reaction of oxygen reduction on the $\mathrm{Cu}$ part. After $168 \mathrm{~h}$ of immersion, the diffusion-controlled process was even more marked on the diagrams for the assembly with cavities (Fig. 12d) and could be also noted for the assembly without cavities (Fig. 12c). This conclusion could be related to those of Håkansson et al. who showed that, for a $\mathrm{Al} /$ carbon couple, the rate controlling mechanism was solely the mass transport of oxygen through the gelatinous $\mathrm{Al}(\mathrm{OH})_{3}$ inside the crevice [43].

In order to quantitatively analyse the LEIS diagrams, three parameters were graphically extracted: the CPE values ( $\alpha$ and $Q)$ and the values of the impedance modulus at $1 \mathrm{~Hz}\left(|\mathrm{Z}|_{1 \mathrm{~Hz}}\right)$. Fig. 13 shows the variation of these parameters for each diagram obtained over the $\mathrm{Al}$ and $\mathrm{Cu}$ parts. Independently of the assembly and of the immersion time, $|\mathrm{Z}|_{1 \mathrm{~Hz}}$ values for the $\mathrm{Cu}$ part were higher than those for the $\mathrm{Al}$ part, which confirmed the differences in reactivity between the two metals when they were coupled (Fig. 13a, d). On the $\mathrm{Cu}$ part, the low frequency range was related to the diffusion process linked to the oxygen reduction (Fig. 12). Whatever the assembly, the increase of $|\mathrm{Z}|_{1 \mathrm{~Hz}}$ between $24 \mathrm{~h}$ and $168 \mathrm{~h}$ of immersion was in good agreement with the shift of the corrosion potentials measured for the assemblies towards more and more negative values from $24 \mathrm{~h}$ to $168 \mathrm{~h}$ of immersion (Fig. 9): this was linked to a more and more significant cathodic polarization for the $\mathrm{Cu}$ part. When the immersion time increased, in agreement with the corrosion potential values measured for the two assemblies, the differences in $|\mathrm{Z}|_{1 \mathrm{~Hz}}$ values between the $\mathrm{Al}$ and $\mathrm{Cu}$ parts were even more marked for the assembly with cavities. After $168 \mathrm{~h}$ of immersion, $|\mathrm{Z}|_{1 \mathrm{~Hz}}$ values measured on the $\mathrm{Al}$ part for the assembly with cavities were lower than those of the Al part for the assembly without cavities. This was explained by taking into account the increase of the electrochemical processes in a confined medium previously showed for the cable: the effect of the galvanic coupling 

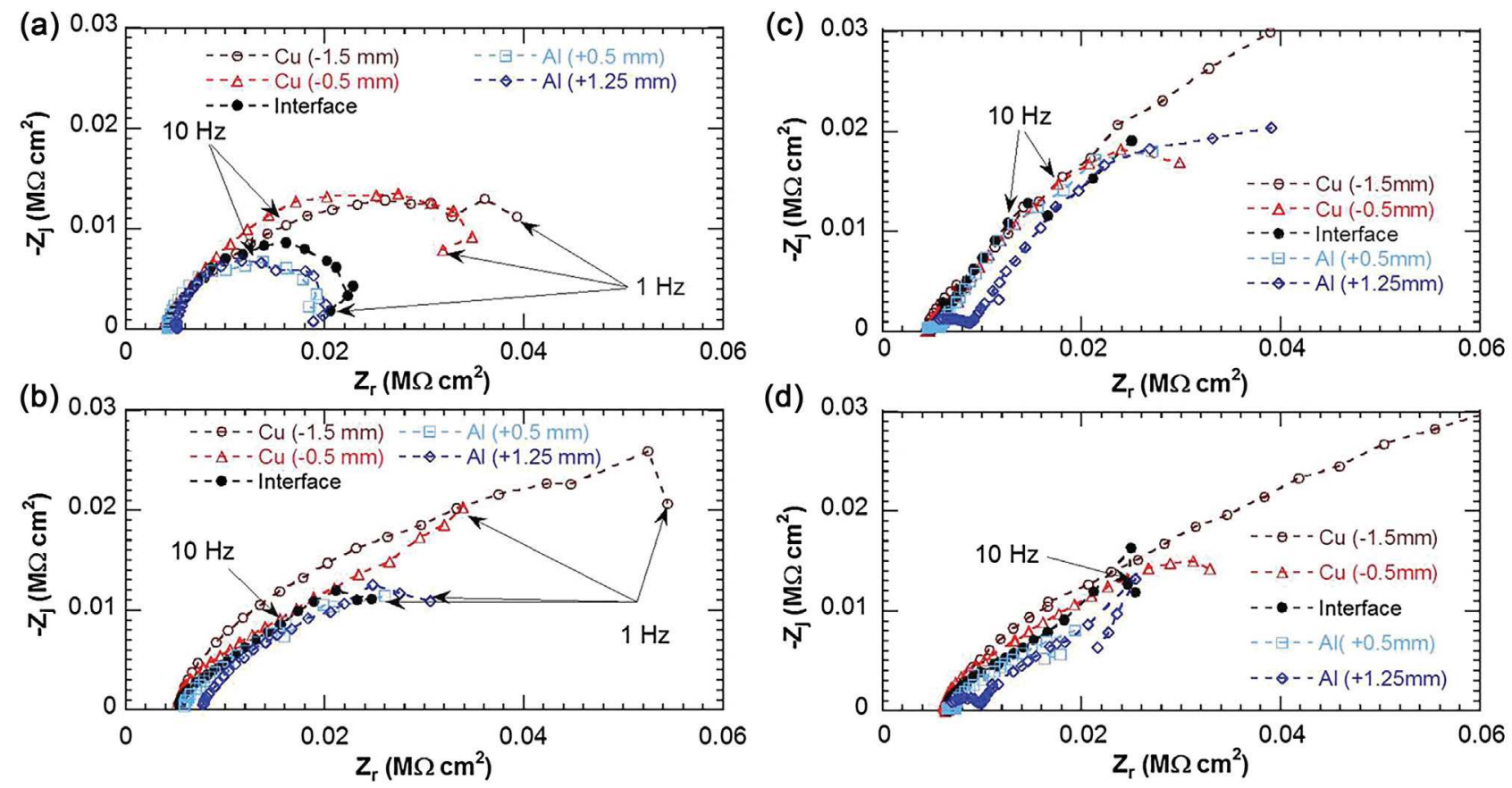

Fig. 12. Local impedance spectra obtained after (a, b) $24 \mathrm{~h}$ and (c, d) $168 \mathrm{~h}$ of immersion at $\mathrm{E}_{\mathrm{corr}}$ in $0.001 \mathrm{M}$ NaCl solution for different positions of the bi-electrode above the $\mathrm{Al} / \mathrm{Cu}$ assemblies: (a, c) without cavities and (b, d) with cavities. Impedance values are calculated taking into account an analyzed surface of 1 mm ${ }^{2}$.
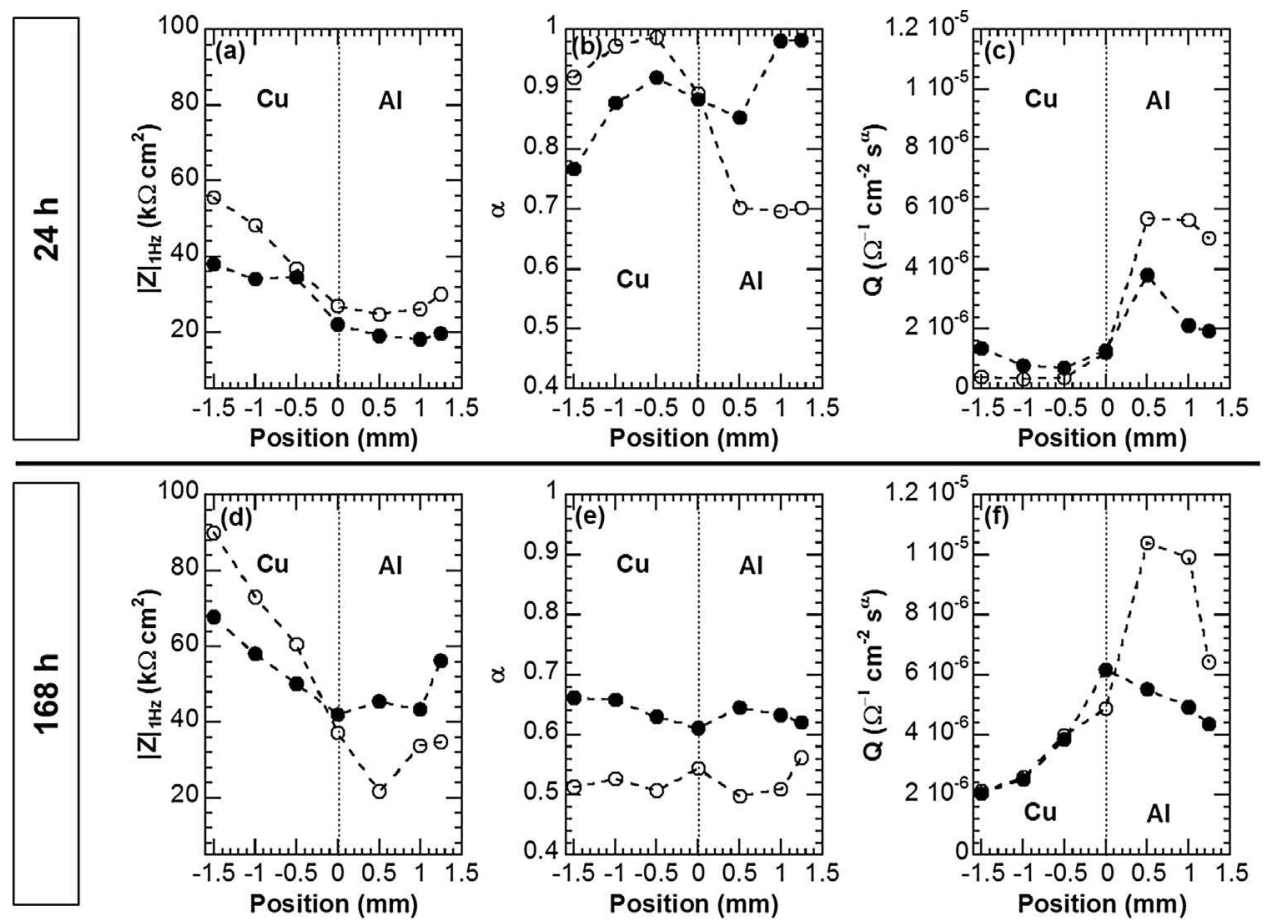

Fig. 13. Variation of the parameters ((a) and (d) $|\mathrm{Z}|_{1 \mathrm{~Hz}}$, (b) and (e) $\alpha$ and (c) and (f) $Q$ ) obtained from the local impedance spectra after different exposure times in $0.001 \mathrm{M}$ $\mathrm{NaCl}$ and for different positions of the bi-electrode over the $\mathrm{Al} / \mathrm{Cu}$ assemblies: $(\bullet)$ without cavities and $(\bigcirc)$ with cavities. Impedance values are calculated taking into account an analyzed surface of $1 \mathrm{~mm}^{2}$.

was more and more marked with increasing immersion time for the assembly with cavities.

The differences in reactivity between $\mathrm{Cu}$ and $\mathrm{Al}$ from one part, and between the two assemblies for the other part, were confirmed by the variation of $\alpha$ and $Q$ with increasing immersion time. After $24 \mathrm{~h}$ of immersion, the strong reactivity at the $\mathrm{Al} / \mathrm{Cu}$ interface was showed with both the decrease of $\alpha$ and the increase of $Q$ in the zone where SEM micrographies (Fig. 10e) showed a crevice on the Al part. This evolution was more marked for an assembly with cavities in relation with a lower corrosion resistance of the Al part due to the penetration of the electrolyte inside the cavities of the cable. After $168 \mathrm{~h}$ of immersion, $\alpha$ and $\mathrm{Q}$ values confirmed the increase of the 
galvanic coupling effect. Between $24 \mathrm{~h}$ and $168 \mathrm{~h}$ of immersion, $\alpha$ values significantly decreased in agreement with an increase of the diffusion processes on the $\mathrm{Cu}$ part and a stronger corrosion for the Al part. Moreover, it can be seen that after $168 \mathrm{~h}$ of immersion, $\alpha$ values are lower for both the $\mathrm{Cu}$ and $\mathrm{Al}$ parts for the assembly with cavities as compared to the assembly without cavities. The result could be linked to a stronger increase of $\mathrm{Q}$ values at the $\mathrm{Al} / \mathrm{Cu}$ interface observed for the assembly with cavities as compared to the assembly without cavities. The results were in good agreement with the presence of the confined electrolyte which amplified the effect of the galvanic coupling when the immersion time increased.

Therefore, the LEIS measurements provided evidence that the corrosion behaviour of the $\mathrm{Al} / \mathrm{Cu}$ assembly was explained by both the galvanic coupling between the $\mathrm{Al}$ and $\mathrm{Cu}$ parts, which enhanced the corrosion of the $\mathrm{Al}$ part, and the penetration of the electrolyte inside the cavities observed in the Al part of the assembly, which led to a more and more confined and aggressive electrolyte with increasing immersion time so that it enhanced the reactivity of the $\mathrm{Al}$ part and thus the galvanic coupling with $\mathrm{Cu}$.

\section{Conclusions}

The study was first focussed on the corrosion behaviour of an $\mathrm{Al}$ (AA1370) cable as compared to a strand.

1. OM observations after exposure to a chloride-containing sulphate solution showed a more extended corrosion damage for the cable than for the strand.

2. Electrochemical measurements showed for the cable: (i) a stronger decrease of the corrosion potential with time than for the strand, (ii) an increase of the anodic current density associated with a pseudo-passivity plateau and a more negative pitting potential as compared to the strand and (iii) impedance diagrams characteristic of a porous system.

3. The corrosion behaviour of the Al cable was controlled by the penetration of the electrolyte between the strands constitutive of the cable. Such a phenomenon led to a more aggressive confined medium which explained the lower corrosion resistance of the cable as compared to the strand.

4. Then, the corrosion behaviour of the assembly between an $\mathrm{Al}$ cable and a $\mathrm{Cu}$ connector was investigated by electrochemical techniques, and in particular local impedance measurements.

5. Al dissolution occurred due to galvanic coupling with the $\mathrm{Cu}$ connector and crevice corrosion was observed on the $\mathrm{Cu}$ walls perpendicularly to the $\mathrm{Al} / \mathrm{Cu}$ interface exposed to the electrolyte.

6. Local impedance data showed that the cavities of the Al cable significantly influenced the corrosion behaviour of the assembly: the reactivity at the $\mathrm{Al} / \mathrm{Cu}$ interface and the extent of the corrosion damage on the Al part were stronger for the assembly with cavities.

\section{References}

[1] Y. Yamano, T. Hosokawa, Development of aluminum wiring harness, SEI Tech. Rev. 73 (2011) 73-80.

[2] A. Laurino, E. Andrieu, J.P. Harouard, J. Lacaze, M.C. Lafont, G. Odemer, C. Blanc, Corrosion behavior of 6101 aluminum alloy strand for automotive wires, J. Electrochem. Soc. 160 (2013) 5069-5575.

[3] K. Yoshida, K. Doi, Improvement of ductility of aluminum wire for automotive wiring harness by alternate drawing, Procedia Eng. 81 (2014) 706-711.

[4] S. Koch, H. Antrekowitsch, Aluminum Alloys for wire harnesses in automotive engineering, Berg Huettenmaenn Monatsh 152 (2007) 62-67.

[5] S.-I. Matsuaka, H. Imai, Direct welding of different metals used ultrasonic vibration, J. Mater. Process. Technol. 209 (2009) 954-960.

[6] J.W. Yang, B. Cao, X.C. He, H.S. Luo, Microstructure evolution and mechanica properties of $\mathrm{Cu}-\mathrm{Al}$ joints by ultrasonic welding, Sci. Technol. Weld. Join. 19 (2014) 500-504
[7] R. Rambat, A.J. Davenport, G.M. Scamans, A. Afseth, Effect of iron-containing intermetallic particles on the corrosion behaviour of aluminum, Corros. Sci. 48 (2006) 3455-3471.

[8] J.O. Park, C.H. Paik, R.C. Alkire, Scanning Microsensors for measurement of local pH distributions at the microscale, J. Electrochem. Soc. 143 (1996) 174-176.

[9] O. Seri, M. Imaizumi, The dissolution of $\mathrm{FeAl}_{3}$ Intermetallic compound and deposition on aluminum in $\mathrm{AlCl}_{3}$ solution, Corros. Sci. 30 (1990) 1121-1133.

[10] J. Xu, W. Chen, Behavior of wire in parallel wire stayed cable under general corrosion effects, J. Constr. Steel Res. 85 (2013) 40-47.

[11] Y. Ishikawa, S. Kawakami, Effects of salt corrosion on the adhesion of brass plated steel cord to rubber, Rubber Chem. Technol. 59 (1986) 1-15.

[12] J.J. Perdomo, I. Song, Chemical and electrochemical conditions on steel under disbonded coatings: the effect of applied potential, solution resistivity, crevice thickness and holiday size, Corros. Sci. 42 (2000) 1389-1415.

[13] S.H. Zhang, S.B. Lyon, Anodic processes on iron covered by thin: dilute electrolyte layers (I)-anodic polarisation, Corros. Sci. 36 (1994) 1289-1307.

[14] R. Oltra, B. Malki, F. Rechou, Influence of aeration on the localized trenching on aluminum alloys, Electrochim. Acta 55 (2010) 4536-4542.

[15] S. Chanel, N. Pébère, An investigation on the corrosion of brass-coated steel cords for tyres by electrochemical techniques, Corros. Sci. 43 (2001) 413-427.

[16] D. Wong, L. Swette, Aluminum corrosion in uninhibited ethylene glycol-water solutions, J. Electrochem. Soc. 126 (1979) 11-15.

[17] M.G.A. Khedr, A.M.S. Lashien, The role of metal cations in the corrosion and corrosion inhibition of aluminum in aqueous solutions, Corros. Sci. 33 (1992) $137-151$

[18] M.G.A. Khedr, A.M.S. Lashien, Corrosion behavior of aluminum in the presence of accelerating metal cations and inhibition, J. Electrochem. Soc. 136 (1989) 968-972.

[19] J.-B. Jorcin, C. Blanc, N. Pébère, B. tribollet, V. Vivier, Galvanic coupling between pure copper and pure aluminum, J. Electrochem. Soc. 155 (2008) C46-C51.

[20] C. Blanc, N. Pébère, B. Tribollet, V. Vivier, Galvanic coupling between copper and aluminum in a thin-layer cell, Corros. Sci. 52 (2010) 991-995.

[21] S. Joma, M. Sancy, E. Sutter, T.T.M. Tran, B. Tribollet, Incongruent dissolution of copper in Al-Cu alloys: influence of local pH changes, Surf. Interface Anal. 45 (2013) 1590-1596.

[22] P. De Lima-Neto, J.P. Farias, L.F.G. Herculano, H.C. De Miranda, Determination of the sensitized zone extension in welded AISI 304 stainless steel using non-destructive electrochemical techniques, Corros. Sci. 50 (2008) 1149-1155.

[23] G. Baril, C. Blanc, M. Keddam, N. Pébère, Local electrochemical impedance spectroscopy applied to the corrosion behavior of an AZ91 magnesium alloy, J. Electrochem. Soc. 150 (2003) 488-493.

[24] S. Marcelin, N. Pébère, Synergistic effect between 8-hydroxyquinoline and benzotriazole for the corrosion protection of 2024 aluminium alloy: a local electrochemical impedance approach, Corros. Sci. 101 (2015) 66-74.

[25] M. Mouanga, M. Puiggali, B. tribollet, V. Vivier, N. Pébère, O. Devos, Galvanic corrosion between zinc and carbon steel investigated by local electrochemical impedance spectroscopy, Electrochim. Acta 88 (2013) 6-14.

[26] D. Sidane, E. Bousquet, O. Devos, M. Puiggali, M. Touzet, V. Vivier, A Poulon-Quintin, Local electrochemical study of friction stir welded aluminum alloy assembly, J. Electroanal. Chem. 737 (2015) 206-211.

[27] J.-B. Jorcin, M.E. Orazem, N. Pébère, B. Tribollet, CPE analysis by local electrochemical impedance spectroscopy, Electrochim. Acta 51 (2006) $1473-1479$.

[28] J.-B. Jorcin, E. Aragon, C. Merlatti, N. Pébère, Delaminated areas beneath organic coating: a local electrochemical impedance approach, Corros. Sci. 48 (2006) 1779-1790

[29] N.A. Belov, D.G. Eskin, A.A. Aksenov, Multicomponent Phase Diagrams: Applications for Commercial Aluminium Alloys, first edition, Elsevier Ltd, Oxford, 2005

[30] D.D. Macdonald, Reflections on the history of electrochemical impedance spectroscopy, Electrochim. Acta 51 (2006) 1376-1388.

[31] C. Gabrielli, M. Keddam, N. Portail, P. Rousseau, H. Takenouti, V. Vivier, Electrochemical impedance spectroscopy investigations of a microelectrode behavior in a thin-layer cell: experimental and theoretical studies, J. Phys. Chem. 110 (2006) 20478-20485

[32] H.-K. Song, H.-Y. Hwang, K.-H. Lee, L.H. Dao, The effect of pore size distribution on the frequency dispersion of porous electrodes, Electrochim. Acta 45 (2000) 2241-2257.

[33] A. Lasia, Impedance of porous electrodes, J. Electroanal. Chem. 397 (1995) $27-33$.

[34] C. Hitz, A. Lasia, Experimental study and modelling of impedance of the her on porous Ni electrodes, J. Electroanal. Chem. 51 (2001) 213-222.

[35] S. Marcelin, N. Pébère, S. Régnier, Electrochemical investigations on crevice corrosion of a martensitic stainless steel in a thin layer cell, J. Electroanal. Chem. 737 (2015) 198-205.

[36] M. Keddam, A. Hugot-Le-Goff, H. Takenouti, D. Thierry, M.C. Arevalo, The influence of a thin electrolyte layer on the corrosion process of zinc in chloride-containing solutions, Corros. Sci. 33 (1992) 1243-1252.

[37] M.E. Orazem, N. Pébère, B. Tribollet, Enhanced graphical representation of electrochemical impedance data, J. Electrochem. Soc. 153 (2006) B129-B136.

[38] R. Vera, P. Verdugo, M. Orellana, E. Muñoz, Corrosion of aluminium in copper-aluminium couples under a marine environment: influence o polyaniline deposited onto copper, Corros. Sci. 52 (2010) 3803-3810. 
[39] L.B. Coelho, M. Mouanga, M.-E. Druart, I. Recloux, D. Cossement, M.-G. Olivier, A SVET study of the inhibitive effects of benzotriazole and cerium chloride solely and combined on an aluminium/copper galvanic coupling model, Corros. Sci. 110 (2016) 143-156.

[40] H. Shi, E.-H. Han, F. Liu, T. Wei, Z. Zhu, D. Xu, Study of corrosion inhibition of coupled $\mathrm{Al}_{2} \mathrm{Cu}-\mathrm{Al}$ and $\mathrm{Al}_{3} \mathrm{Fe}-\mathrm{Al}$ by cerium cinnamate using scanning vibrating electrode technique and scanning ion-selective electrode technique, Corros, Sci. 98 (2015) 150-162.

[41] N. Murer, R. Oltra, B. Vuillemin, O. Néel, Numerical modelling of the galvanic coupling in aluminium alloys: a discussion on the application of local probe techniques, Corros. Sci. 52 (2010) 130-139.
[42] J. Bernard, M. Chatenet, F. Dalard, Understanding aluminum behavior in aqueous alkaline solution using coupled techniques: part I. Rotating ring-disk study, Electrochim. Acta 52 (2006), 86-93.

[43] E. Håkansson, J. Hoffman, P. Predecki, M. Kumosa, The role of corrosion product deposition in galvanic corrosion of aluminum/carbon systems, Corros. Sci. 114 (2017) 10-16. 